\title{
GOLF COURSES AND THEIR IMPACT ON THE ENVIRONMENT
}

\author{
B. Doytchev* \\ Department of Sports Medicine, Sector Ecology, National Sports Academy \\ "Vassil Levski", Sofia, Bulgaria
}

\begin{abstract}
Golf is a popular and traditional sport in countries like Scotland, UK, USA, Canada, Japan, Australia, Germany, Denmark, etc. Over the last decades, it has gained increasing popularity in many countries around the world, established as tourist, spa recreation and sports destinations. Interest in the sport under discussion has progressively increased over the years. In this article, we only discuss golf courses and their impact on the environment. We will not comment on whether a given golf course is appropriate from a community perspective - a very important issue. This requires the construction of golf courses in accordance with environmental norms and policies, as well as with the development of the ecological culture of society.
\end{abstract}

Key words: golf complexes and golf courses, ecology, pollution, environment.

Golf is a popular and traditional sport in countries such as Scotland, Great Britain, USA, Canada, Japan, Australia, Germany, Denmark, etc.

Over the last decades, it has gained increasing popularity in many countries around the world, established as a tourist, spa recreation and sports destinations. The interest in the sport is progressively increasing over the years. This article discusses only golf courses as they have an impact on the environment. We will not comment on whether a given golf course is appropriate from a community perspective - a very important issue. This requires the construction of golf courses in accordance with environmental norms and policies, as well as with the development of the ecological culture of society.

Golf is a popular and traditional sport in countries such as Scotland, Great Britain, USA, Canada, Japan, Australia, Germany, Denmark, etc. In recent decades, it has been gaining increasing popularity in many

*Correspondence to: Chief Assist. Assoc Boyan Doychev, Ph.D. - NSA, Department of Sports Medicine,Sector Ecology, 1700 Sofia, Studentski Grad countries around the world, established as a tourist, SPA Recreation and sports destinations. The historical development of golf in Bulgaria is reflected in a number of publications by Prof. R. Damyanova [1.3]

This article discusses only golf courses as they have an impact on the environment. We will not comment on whether a given golf course is appropriate from a community perspective - a very important issue. It arises when large amounts of area, suitable for recreation in intensively assimilated areas (especially when this land is located near the urban areas) is used for playing golf. These venues then serve sports and recreational purposes or recreational spas to a relatively limited number of golf players. According to the type and category of golf courses (public, private, mixed, championship, etc.). In order to be able to carry out official golf competitions, each course must comply with all international requirements of the internationally recognized European Handicap System and officially licensed by the relevant Commission [2]. The purpose of these complexes and the very nature of the golf game are reflected in one specific sporting terminology [4.5].

Golf courses are most often multifunctional complexes with different infrastructure: 
- A golf course or several playgrounds, and in some cases the golf complex also includes tennis training grounds, swimming pools designed for people with disabilities (adapted physical activity and sports);

- Driving Range - Training golf course;

- Clubhouse, auxiliary premises and various sub-sites such as: (Hotel, SPA center, restaurant, café-bar, winery, conference hall, toilets, showers, changing rooms, golf office, specially equipped studios, golf simulators, shop for golf accessories or Pro shop);

- Car parking sheds, electric golf carts and equipment storage (golf mowers, water pumps for watering, hydrophore pumps for drainage, etc.);

- Sheds and covers for protection against rain and sun;

- Outdoor lighting for playing early in the morning and at night;

- Road infrastructure (facilitating access);

- Other objects [10].

From an environmental point of view, the large amount of land area needed to build a golf course poses a risk (in habitats with ecologically valuable and sensitive areas, in areas close to the natural state, etc.), but is also positive (in intensively assimilated areas).

The location of the golf course will determine whether it is beneficial or harmful to the environment.

\section{Impact of golf courses on the environment}

The potential impacts of golf courses on the environment, according to the source of the problem are:

- Construction and modeling of the landscape (golf complex, playgrounds, clubhouse, auxiliary premises, various subsites, bunkers, outdoor lighting, sheds, roads, and parking):

- Change in the soil's loosening (compaction by heavy machinery);

- The removal of trees and shrubs on the field used directly for golf;

- Draining marshland on some plots may cause flooding at a later stage;

- Modification or loss of existing water bodies;

- Separation of already bordering habitats;

- Road infrastructure and other landscape changes [7].

- Wastewater disposal (from the clubhouse and auxiliary premises), watering and fertilization of adjacent lawns:
- Damage or alteration in surface water bodies, water systems, and facilities;

- Loss of drinking water for watering, above all in dangerously dry areas or soils that have limited absorption capacity;

- The watering should be limited to the bare minimum in order to conserve water resources. If possible, use water from rainwater tanks instead of drinking water.

- Change in the level of moisture (watering and drainage);

- Contamination of groundwater by sewage or nitrates (intense weed growth in certain areas) that permeate the land area;

- Change in nutrient levels by using chemicals (destroying certain species);

- Pesticides should not be used. Their use should only be considered in exceptional cases and only for a limited period of time (for example, for the treatment of green mold). It is recommended that instead of biological and mechanical means to fight off pests and weed control, the provision of nesting sites for birds and the removal of weeds by mechanical and thermal methods [10];

- The person supervising the golf course must have sufficient knowledge of the environment and environmental protection. A logbook for treatment, registration, and maintenance (including all fertilizer applications) should be kept, taking into account the legal bases set out above and, in particular, all pesticide applications [7].

- $\quad$ Traffic from road transport and auxiliary activities (from golfers, visitors, and club employees):

- Parking places (far enough away from the club building and recreation areas where peace and tranquility is requested);

- Emissions of harmful substances;

- Noise (noise pollution);

- Stress.

- Golf Activities:

- They exert stress on animals and plants, entering the natural areas (ecological zones), in close proximity to the holes in the field;

- They disturb animals that need vast territories around them.

- Secondary impacts:

- The area around the golf course is suitable for building a hotel, 
outbuilding or camping (the golf course increases the attractiveness of the place itself, as it is in a densely populated valley) [9].

\section{Choosing a place:}

Initially, a solution should be found which place for the golf course will be suitable, nonthreatening and environmentally friendly.

Habitats with ecologically valuable and sensitive areas (rich biodiversity, dry grass communities, wetlands, coastal dunes, and ecologically sensitive forest funds) are particularly problematic. Dry areas are threatened and should be avoided due to the high volume of irrigation water that the golf course will need. Wetlands with a high level of groundwater or sandy soils are not suitable for golf courses. The usual practice of lawn maintenance (use of fertilizers and other substances) would endanger groundwater in these areas.

A uniform landscape, consisting mainly of farmland including intensively cultivated landscapes, has less ecological value than the golf course. The construction of a golf course in such an area can increase its value and its ecological and aesthetic characteristics. Thus, where possible, only intensively utilized agricultural land must be absorbed for its conversion into a golf course [8].

A general rule for choosing a golf course venue is: avoiding ecologically valuable and sensitive areas and improving uniform landscapes, including intensively cultivated.

Other characteristics of the locality, which are of importance to the environment, also play a role, namely:

- Using existing buildings (which will make the construction of new buildings unnecessary);

- Linking the terrain to the public sewer system (avoiding the problems caused by wastewater);

- Using the already existing transport infrastructure to access the site (this will eliminate the need to build new roads);

- There should be close and convenient public transport to serve the golfers, visitors, and employees of the club.

\section{Size for the golf course}

The more we have a larger land area allocated to a golf course, the greater the opportunity for:

- Avoiding potential conflicts as golfing can be exercised away from ecologically sensitive areas (we need to make sure that sensitive areas are far away from the course or there are enough buffer zones between several courses);
- Increasing the ecological value of the site: Intensively utilized land can be used for a wide variety of uses, new habitats may be created (eg water banks close to natural water reservoirs overgrown with dense and high non-woody vegetation, including underwater, hedges, and trees) [8].

\section{The layout of the golf course}

Tree-Bush groups (made up of different types of perennial plants and shrubs suitable for the place) and water basins can play the role of natural "obstacles" to the terrain of the course. Buffer zones can be easily converted into lawns that need only minimal maintenance efforts. Such biotopes have undoubtedly only limited environmental value, as they are subject to a relatively high level of disruption from golfers. They can, however, offer a relatively good habitat for species of animals and plants that are resistant to external disturbances. Also, these terrains have a harmonizing visual effect on the overall landscape.

The length, width, shape, and consistency of the "holes" on the course can be easily tailored to meet the needs and characteristics of the environment. The boundary separating the playground and the unaffected biotopes largely found in nature should not be abrupt. On the contrary, golf courses designers have to take advantage of and adapt to allow large and diverse transition areas to evolve with the environment and Biotopite [11].

Sensitive areas of the golf course - those that are easily accessible for entry - should be marked as such to keep the golfers away from them. In fact, golf rules are fully compatible with the warning signs that regulate entry into these areas.

\section{Additional Design recommendations:}

- Use mainly species of trees and shrubs that are most typical for the given locality or to plant new similar species.

- Allow enough open spaces that require minimal maintenance (meadows or parts of meadows that are mowed twice a year, where the natural inheritance of the vegetation develops without interference).

- Allow enough buffer zone (at least $20 \mathrm{~m}$ wide) around so-called "sensitive" areas requiring a high level of conservation. Around the forest area, there must be unused peripheral land at least $10 \mathrm{~m}$ wide, covered with shrubs and perennial plants, on its outskirts [10].

- Restoring streams by being channeled (e.g., to pass through underground pipes or concrete ducts) to their natural state. Nearby 
artificial drainage canals in wetlands should be adaptable to natural conditions.

- Water basins should be left in their natural form to the coastline which in itself creates their connection with the surrounding habitats. The habitats of many amphibians consist of water, meadows, and forests which can not be separated from each other by frequent lawns.

- An underground barrier under the green areas in the protected water basins should e used. Filter the water, and use pumps to irrigate the same areas.

- There should not be rough, untreated land patches but continuous areas of nearby noncultivated land. Playgrounds should not be restricted and divided into layers of almost non-cultivated land.

- Grounds should not be in a rectangular shape.

- Artificial constructions should not be placed in the ground (those that are alien to the landscape), such as fences and nets to catch balls.

- Dams and streams should not be placed in near-natural areas.

- Wastewater should not be drained to nearby streams or lakes.

\section{Maintenance}

The maintenance plan must be formulated in accordance with the environmental principles that will determine how much and what kind of care the different areas of the golf course should receive. Planners need to have a plan that engages them legally regarding the principles of low-intensity maintenance, ready for submission during the formal licensing procedure, which will prevent some conflicts arising later. After construction, certain authorities have to carry out the necessary inspections to make sure that the plan has been implemented [7].

The following development goals for the care of adjacent areas are desirable from an environmental point of view:

- A Variety of Plant Species: For the benefit of the animal world, there is a need to provide a large number of herbs such that their flowering periods cover the whole growing season. This will provide a food base for butterflies and other insects that inhabit the flowers that serve as food for birds, amphibians, and other animals;

- Structural diversity: The vegetation of different heights and densities, creates a mosaic effect within a small area. Thus, different animal representatives can benefit from the variable scale of the terrain.
- Fertilizers should be used only in the absolutely necessary quantity. The Course can be done entirely without them approximately 2 to 3 years after it has been constructed. The grass clippings left on the meadows will allow the food level to remain in balance.

\section{CONCLUSION}

The interest in the sport is progressively increasing over the years. This requires the construction of golf courses in accordance with environmental norms and policies, as well as with the development of the ecological culture of society.

\section{REFERENCES}

1. Damyanova R. Sport for leisure. Nontraditional sports for Bulgaria. Golf - "the game for life". Jubilee Scientific Conference 60th Birthday "TMFF" NSA 28-29 December, "Sports and Science", ext.ed. 2002, pages. 299-308.

2. Damyanova R. European Handicap System Bulgarian version 2004-2005-2006, NSA PRESS, BGA, S., 2004

3. Turley N., R. Damianova. Golf Program for Children. Fifth International Scientific Conference "TMFV" NSA December 2006, "Sports and Science", ext.ed. 1/2007, pages. 391-396.

4. Damyanova R. English-Bulgarian Golf Dictionary 1. NSA Press, S., 2004

5. Damyanova R. English-Bulgarian Dictionary of Golf 2. NSA Press, Bulged, S., 2009

6. Bay LFU (Bayer. State Office for Environmental Protection) and ANL (Academy for Nature Conservation and Landscape Care): Nature Conservation and Golf. Memorabilia for landscape management and conservation 2, Munich 1989.

7. BISP (Federal Institute of Sports Science): Planning, construction and maintenance of golf courses. Series Sports and Leisure Facilities, Planning Basics P1, Cologne 1987.

8. Haber, W.: For the landscape ecological assessment of golf courses. In: Golf magazine, H. 3, 1983.

9. Ministry F. Environment Baden-Württemberg (ed.): Guide to the landscape-related assessment and planning of golf courses LFU, Karlsruhe 1989.

10. Schemel, H.J .: Environmentally Compatible Leisure Facilities - A Guide to Testing Skiing, Water and Golfing Projects from an Environmental Perspective, Vol. 1 (Analysis and Assessment), Reports by the Federal Environmental Agency, Vol. 5, 1987.

11 . Wolf, $\mathrm{G} .:$ Protection and care of biotopes and golf courses. In: Garden and Landscape, H. 6, 1986. 